UNIO - EU Law Journal. Vol. 3, N. . 2, Julho 2017, pp 175-184.

®2017 Centro de Estudos em Direito da União Europeia

Escola de Direito - Universidade do Minho
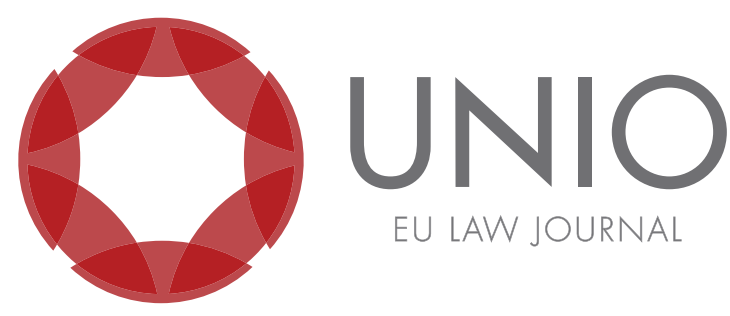

EU LAW JOURNAL

\title{
A transposição da Diretiva Private Enforcement: perspetiva crítica
}

\author{
Maria José Costeira*
}

SUMÁRIO: Este artigo analisa a proposta de transposição da Diretiva Private Enforcement para o ordenamento jurídico português. O escrito examina diversos aspetos do anteprojeto nacional, que passou por consulta pública, mas, sobretudo, realça os artigos sobre definições, responsabilidade, meios de prova e os potenciais impactos que a norma poderá ter na organização do sistema judicial português. Critica ainda as incoerências do anteprojeto e indica alguns aspectos problemáticos desta proposta e as alterações necessárias que devem ser feitas para tornar o diploma mais sólido.

PALAVRAS-CHAVE: Diretiva Private Enforcement - direito da concorrência-ordenamento jurídico português - proposta de transposição - organização judiciária.

\footnotetext{
* Juíza portuguesa no Tribunal Geral do Tribunal de Justiça de União Europeia.
} 
A 26 de novembro de 2014 foi aprovada a Diretiva 2014/104/UE do Parlamento Europeu e do Conselho relativa a certas regras que regem as ações de indemnização no âmbito do direito nacional por infrações às disposições do direito da concorrência dos Estados-Membros e da União Europeia. A referida diretiva, usualmente denominada diretiva enforcement, deverá ser transposta pelos Estados-Membros até dia 27 de dezembro de 2016 (artigo 21. ${ }^{\circ}$ ).

Em Portugal coube à Autoridade da Concorrência (AdC) a tarefa de preparar a transposição da diretiva, tendo divulgado, a 22 de junho de 2016, a última proposta de anteprojeto de transposição da diretiva, anteprojeto esse que resultou de um processo de discussão pública.

É esta última versão que serve de base à presente comunicação, na qual se pretende chamar a atenção para alguns aspectos que poderão ser aperfeiçoados. Intencionalmente, por se tratar de matéria cuja discussão não se compadece com o tempo disponível, ficam fora desta análise aspectos como a quantificação do dano ou o acesso a meios de prova, recaindo a análise apresentada essencialmente sobre os artigos 2. - "Definições" -, 3. - "Responsabilidade civil" -, 7. - "Força probatória das decisões das autoridades de concorrência e dos tribunais de recurso" - e 22. "Alterações à Lei de Organização do Sistema Judiciário".

\section{(i) Artigo 2." "Definições"}

Este artigo elenca uma série de definições e conceitos que são referidos ao longo da proposta de diploma, à semelhança do artigo $2 .^{\circ}$ da diretiva. Optou-se por incluir definições que não constam do artigo homólogo da diretiva, por inverter a ordem de outras e por suprimir outras.

No que toca à inclusão de conceitos que não constam no artigo $2 .^{\circ}$ da diretiva, destacam-se as noções de "cartel" e de "resolução extrajudicial de litígios" - alíneas c) e r).

\section{alínea c) "Cartel”}

"Cartel), o acordo ou prática concertada entre duas on mais empresas concorrentes que vise coordenar o seu comportamento concorrencial no mercado ou influenciar os parâmetros relevantes da concorrência, através de condutas como, nomeadamente, fixar ou coordenar os preços de aquisição ou de venda ou outras condições de transação, incluindo relativamente a direitos de propriedade inteletual, atribuir quotas de produção ou de venda, repartir mercados e clientes, incluindo a concertação em leilôes e concursos públicos, restringir importaçöes ou exportações ou conduzir açōes anticoncorrenciais contra outros concorrentes, tal como proibido pelo artigo 9. a Lei n. 19/2012, de 8 de maio, e, se aplicável, pelo artigo 101. 'do TFUE"

As infrações ao direito da concorrência estão consagradas em diploma próprio: a Lei da Concorrência (LdC), aprovada pela Lei n. ${ }^{\circ}$ 19/2012 de 8 de maio. Esta proposta de anteprojeto não visa alterar, definir ou de qualquer outro modo dispor sobre tais infrações, como resulta expressamente do seu artigo $10^{\circ}$ e da exposição de motivos que acompanha a proposta. Está em causa tão só regular alguns aspetos das ações de indemnização por infração às regras do direito da concorrência.

Ora, a inclusão neste anteprojeto da noção de "cartel", típica infração ao direito da concorrência, afigura-se desde logo desnecessária, dado que tal infração está tipificada, e bem, no artigo 9. ${ }^{\circ}$ da LdC. Para além de desnecessária, é ainda contraproducente na medida em que a caraterização aqui feita de cartel não coincide com a noção do mesmo 
constante do referido artigo 9.', potenciando-se, por esta via, dúvidas interpretativas desnecessárias e inúteis.

\section{alínea r) "resolução extrajudicial de litígios"}

«Resolução extrajudicial de litígios», qualquer mecanismo que permita às partes resolverem extrajudicialmente o litígio respeitante ao pedido de indemnização, nomeadamente a mediação, a conciliação, a arbitragem e a transação prevista no artigo 1248. do Código Civil

Resolução extrajudicial de litígios é a designação genérica de todas as formas alternativas de resolução de litígios face ao que podemos apelidar de modo tradicional ou convencional e que consiste no recurso aos tribunais. A mediação, a arbitragem e a conciliação são as formas típicas de resolução extrajudicial de litígios. A transação, por seu lado, pode ser uma forma alternativa de resolução de um litígio ou não, isto é, a transação é possível, e diria mesmo algo frequente, no decurso de um processo judicial. Neste caso, sendo uma forma amigável e consensual de resolução do litígio não é uma resolução extrajudicial tout court, desde logo porque implica uma decisão judicial homologatória.

A opção de definir, numa lei que pretende regular algumas especificidades de um determinado tipo de ações cíveis, as formas possíveis de resolução extrajudicial de litígios, parece-me desnecessária já que nada sendo dito em contrário todas elas são possíveis.

Note-se que a diretiva define "resolução amigável de litígios", não resolução extrajudicial de litígios, e fá-lo como qualquer mecanismo de resolução extrajudicial do litígio que permita às partes chegarem a um acordo quanto ao pedido de indemnização (artigo 2. ${ }^{\circ}$, ponto 21), o que é bem diferente de enunciar as formas de resolução extrajudicial dos litígios.

No que toca à supressão de algumas definições que constam da diretiva, chamo a atenção para as definições de "ação de indemnização" e "pedido de indemnização". Pode perguntar-se: será que era necessário incluir essas definições? Talvez não. Mas o certo é que também não há necessidade de definir "acordo extrajudicial” [alínea a)] ou infração ao direito da concorrência [alínea k)] e estas definições constam da norma em análise.

No que toca à mudança de nomenclatura os conceitos respeita, destacam-se as noções de decisão definitiva e de meios de prova preexistentes.

\section{alínea h) "Decisão definitiva"}

"Uma decisão de uma autoridade de concorrência que não pode ou já não pode ser objeto de recurso ordinário".

Note-se que a diretiva define não decisão definitiva mas sim "decisão definitiva em matéria de infração", que refere ser "uma decisão em matéria de infração que não pode ou já não pode ser objeto de recurso ordinário", ou seja, abrange as decisões das autoridades nacionais e as decisões dos tribunais.

No anteprojeto opta-se por definir apenas como decisão definitiva as decisões das autoridades da concorrência, complicando-se desnecessariamente a redação dos artigos $5 .^{\circ}$, n. 3 , al. b) $6^{\circ} .^{\circ}$ n. ${ }^{\circ} 5,7^{\circ}$, n. $^{\circ} 1$ e 2 e potenciando-se a controvérsia sobre uma questão que não merece discussão. 


\section{alínea o) "Meios de prova preexistentes"}

"Meios de prova que existam independentemente de uma investigação de uma autoridade da concorrência, quer constem ou não do processo da autoridade da concorrência".

A diretiva define com o mesmo conteúdo "informações preexistentes" (artigo 2. ${ }^{\circ}$, n. $\left.^{\circ} 17\right)$.

Se é certo que estão de facto em causa meios de prova, o facto é que entre nós esta designação - "Meios de prova preexistentes" - não sendo muito corrente, tem um significado diferente. Quando se fala de prova preexistente está-se a falar da prova pré-constituída, ou seja, da prova produzida antes do surgimento da demanda. A preexistência refere-se à ação judicial.

Sendo este o conceito de prova preexistente no nosso ordenamento jurídico, parece pouco correto falar aqui de meios de prova preexistentes para referir meios de prova que existam independentemente de uma investigação da $\mathrm{AdC}$ uma vez que não são verdadeiros meios de prova "preexistentes a" mas sim "existentes independentemente de".

\section{(ii) Artigo 3. ${ }^{\circ}$ Responsabilidade civil}

Este artigo, um dos mais importantes, apresenta algumas imperfeições que me parecem graves. Vejamos.

n. 1 "A empresa on associação de empresas que cometer uma infração ao direito da concorrência fica obrigada a indemnizar integralmente os lesados pelos danos resultantes de tal infração."

O artigo 3. ' da diretiva, sob a epígrafe "Direito à reparação integral", dispõe que:

"Os Estados-membros asseguram que as pessoas singulares ou colectivas que sofram danos causados por infração ao direito da concorrência possam pedir e obter a reparação integral desses danos".

Ora, a redação da proposta de diploma de transposição é substancialmente diferente da redação do artigo da diretiva. De facto, é diferente dizer que os lesados têm direito à reparação dos danos ou que os infratores ficam obrigados a indemnizar.

No caso em análise, parece mais correta a redação da diretiva porque na verdade a obrigação de indemnização só existe se ficarem provados, além da infração, os restantes pressupostos da responsabilidade civil, designadamente o dano e o nexo de causalidade entre a infração e o dano. Logo, não se pode dizer que os infratores têm uma obrigação direta e imediata de pagar uma indemnização, sendo mais adequado dizer que os lesados têm direito a uma indemnização.

A redação escolhida permite que se defenda que basta a prova da infração para, havendo danos, nascer a obrigação de indemnizar quando, na verdade, a prova do nexo de causalidade é essencial.

Note-se que o considerando 11 da diretiva, para além de se referir expressamente ao nexo de causalidade, esclarece que:

"Caso os Estados-membros estabeleçam outras condições de reparação no âmbito do direito nacional, como a imputabilidade, a adequação ou a culpabilidade, deverão poder mantê-las, desde que respeitem a jurisprudência do Tribunal de Justiça, os princípios da efectividade e da equivalência e a presente diretiva".

n. 2 "Quando uma empresa incluir uma pluralidade de pessoas jurídicas, a atuação de uma pessoa jurídica é igualmente imputável à pessoa ou pessoas jurídicas que com ela constituem uma unidade económica ou mantêm laços de interdependência e que sobre ela tenham exercido influência determinante."

O que se pretende aqui é englobar os grupos de empresas tal como definidos 
nos artigos $488 .^{\circ}$ e $489 .^{\circ}$ do Código das Sociedades Comerciais e responsabilizar as empresas dominantes (empresas-mãe) pelas infrações cometidas pelas empresasdominadas (como resulta expressamente do n. ${ }^{\circ} 3$ deste artigo).

A terminologia utilizada está em desarmonia com a linguagem jurídica com tradição entre nós. Com efeito, no nosso ordenamento jurídico não se usam expressões como "pluralidade de pessoas jurídicas" nem se dispõe que "a atuação de uma pessoa jurídica é igualmente imputável a outra pessoa jurídica".

Com efeito, nem as empresas incluem uma pluralidade de pessoas jurídicas nem as infrações cometidas por uma empresa são imputáveis a outra. As empresas estão ou podem estar em relações de grupo ou/e domínio. Por outro lado, não é a imputação que se transmite. O que se pode transmitir é a responsabilidade resultante da atuação infractora.

De acordo com o Coódigo das Sociedades Comerciais, as empresas mães sociedade dominante - são responsáveis pelas obrigações das empresas dominadas - sociedade dominada (artigo 501. ${ }^{\circ}$, ex vi artigo 491. ${ }^{\circ}$ ).

Face ao n. 3 deste artigo ("presume-se que uma pessoa jurídica exerce influência determinante sobre outra pessoa jurídica quando detém a totalidade do seu capital social') parece claro que se está a querer referir de empresas em relação de domínio total. Por conseguinte, deveria optar-se por uma redação mais consentânea com a linguagem jurídica existente entre nós.

\section{(iii) Artigo 7. "Força probatória das decisões das autoridades de concorrência e dos tribunais de recurso"}

De acordo com o n. ${ }^{\circ} 1$ deste artigo:

"A declaração pela Autoridade da Concorrência, através de decisão definitiva, ou por um tribunal de recurso, através de decisão transitada em julgado, da existência de uma infração ao direito da concorrência constitui presunção inilidivel da existência, natureza e âmbito material, pessoal, temporal e territorial dessa infração, para efeitos da ação de indemnização pelos danos dela resultantes".

Este artigo resulta da transposição do artigo 9. ${ }^{\circ}$ da diretiva e pode dizer-se que, em certa medida, consagra um alargamento do alcance do já previsto no artigo 16. ${ }^{\circ}$, n. ${ }^{\circ}$ 1, do Regulamento (CE) 1/2003 do Conselho de 16 de dezembro relativamente às decisões da Comissão.

O que resulta deste artigo, como já resultava do referido artigo $16^{\circ}$ no que concerne à Comissão, é que numa ação por infração das regras de concorrência em que tenha havido já uma decisão definitiva da $\mathrm{AdC}$, confirmada pelos tribunais caso tenha sido objecto de recurso, o tribunal não pode apreciar a existência da infração, ou seja, tem-se à partida por provada a existência da infração, incluindo-se aqui a existência, natureza e âmbito material, pessoal, temporal e territorial dessa infração. Na proposta opta-se pelo conceito de presunção inilidível que me parece correta.

Questionou-se já a legalidade do referido artigo $16 .^{\circ}$ e, nomeadamente, a sua compatibilidade com o artigo $47 .^{\circ}$ da Carta dos Direitos Fundamentais da União Europeia (que assegura, no direito da União, a proteção conferida pelo artigo $6 .^{\circ}$, n. $^{\circ}$, da $\mathrm{CEDH}$ ) que consagra o princípio da protecção jurisdicional efetiva, princípio que engloba os direitos de defesa, o princípio da igualdade de armas, o direito de acesso aos tribunais assim como o direito de aconselhamento, defesa e representação.

Com efeito, pode perguntar-se se, ficando o tribunal impedido de apreciar da existência de uma infração, não se está de algum modo a limitar o direito a uma protecção jurisdicional efetiva na medida em que não se permite à parte defender-se no 
que à prática da infração respeita pois esta está já dada como assente.

A esta questão já o Tribunal de Justiça respondeu, esclarecendo de forma clara por que razão o artigo $16 .^{\circ}$ do regulamento não viola o artigo $47 .^{\circ}$ da Carta (Cfr. Ac. Europese, C-199/11, 6 de novembro de 2012).

$\mathrm{E}$ as razões são, em suma, as seguintes:

1) A aplicação das regras de concorrência da União assenta num dever de cooperação leal entre, por um lado, os órgãos jurisdicionais nacionais e, por outro, respetivamente, a Comissão e os órgãos jurisdicionais da União, no quadro do qual cada um atua em função do papel que lhe é atribuído pelo Tratado, cabendo a competência exclusiva para fiscalizar a legalidade dos atos das instituições da União aos órgãos jurisdicionais da União e não aos órgãos jurisdicionais nacionais. Estes não têm o poder de declarar tais atos inválidos (jurisprudência pacífica desde o Ac. Foto-frost)

2) A regra segundo a qual os órgãos jurisdicionais nacionais não podem tomar decisões que sejam contrárias a uma decisão da Comissão relativa a um processo de aplicação do artigo 101. ${ }^{\circ}$ TFUE é por isso uma expressão específica da repartição de competências, na União, entre, por um lado, os órgãos jurisdicionais nacionais e, por outro, a Comissão e os órgãos jurisdicionais da União.

3) O direito da União prevê um sistema de fiscalização jurisdicional das decisões da Comissão relativas aos processos de aplicação do artigo 101. 'TFUE que oferece todas as garantias exigidas pelo artigo $47 .^{\circ}$ da Carta.

4) A fiscalização prevista pelos Tratados implica que o juiz da União exerça uma fiscalização tanto de direito como de facto e que tenha o poder de apreciar as provas, de anular a decisão impugnada e de alterar o montante das coimas.

5) Uma ação cível de indemnização implica não apenas a verificação da ocorrência de um facto danoso mas igualmente a existência de um prejuízo e de um nexo direto entre este e o referido facto danoso.

Assim, embora seja verdade que a obrigação do juiz nacional de não tomar decisões que sejam contrárias à decisão da Comissão que declara uma infração ao artigo 101. ${ }^{\circ}$ TFUE obriga esse juiz a concluir pela existência de um cartel ou de uma prática proibida, há que precisar que a verificação de um prejuízo e de um nexo de causalidade direta entre esse prejuízo e o cartel ou a prática em causa continua, em contrapartida, sujeita à apreciação do juiz nacional.

Este mesmo raciocínio pode ser transposto para as decisões da AdC. Deixando de fora a primeira série de argumentos, relacionada com o dever de cooperação leal entre as instituições da União e os órgãos jurisdicionais nacionais, por não ser aplicável, a segunda série de argumentos tem entre nós inteira aplicação. Por um lado, das decisões da AdC há recurso de plena jurisdição para um tribunal nacional, garantindo-se assim que, caso a infratora não se tenha conformado com a decisão e tenha interposto recurso, teve já direito a um julgamento absolutamente isento e imparcial onde se pode defender. Por outro lado, é no processo em que é pedida uma indemnização que cabe fazer a prova da existência de um dano e do nexo de causalidade entre este e a infração.

Fica pois perfeitamente assegurado o princípio da proteção jurisdicional efetiva.

Diferente é a situação consagrada nos n. ${ }^{\text {os }} 2$ e 3 deste artigo:

"2 - A declaração por uma autoridade de concorrência de qualquer Estado-Membro da União, através de decisão definitiva, da existência de uma infração ao direito da concorrência constitui presunção ilidivel da existência, natureza e âmbito material, pessoal, temporal e territorial dessa infraşão, para efeitos da ação de indemnização pelos danos dela resultantes".

" 3 - A declaração por um tribunal de recurso de outros Estados-Membros da União, através 
de decisão transitada em julgado da existência de uma infração ao direito da concorrência constitui presunção ilidivel da existência, natureza e âmbito material, pessoal, temporal e territorial dessa infração, para efeitos da ação de indemnização pelos danos dela resultantes".

A diretiva a propósito das decisões proferidas pelas autoridades e tribunais de outros Estados-Membros impõe que elas possam ser apresentadas em tribunal "pelo menos como elemento de prova prima facie de uma infração ao direito da concorrência".

$\mathrm{Na}$ transposição deste preceito o legislador nacional conferiu às decisões de autoridades e tribunais de outros Estados-Membros a força de presunção ilidível da infração.

Recuando um pouco, a redação original dos n. ${ }^{\text {os }} 2$ e 3 deste artigo estendia esta vinculação e o carácter de presunção inilidível às decisões das autoridades nacionais e dos tribunais dos demais países da União. Depois do processo de discussão pública da proposta, alterou-se a natureza da presunção que se qualificou de presunção ilidível.

Presunções são, tal como define o artigo 349. ${ }^{\circ}$ do Código Civil, "as ilações que a lei ou o julgador tira de um facto conhecido para firmar um facto desconhecido." Se a presunção for inilidível, quem a tem a seu favor, não tem de fazer prova do facto a que ela conduz. Se for ilidível, admite prova em contrário a cargo da pessoa contra quem funciona a presunção (artigo 350..$^{\circ}$ do Código Civil).

Isto significa que numa típica ação cível de indemnização por violação do direito da concorrência, a infração presume-se cabendo ao(s) réu(s) demonstrar que, não obstante a condenação anterior, a infração não existiu.

Ao contrário do que se passa no caso de decisões condenatórias da AdC, neste caso a opção consagrada deve ser ponderada. Com efeito, por um lado, no universo dos 28 Estados-Membros, as autoridades nacionais da concorrência não têm todas a mesma natureza e independência. Por outro lado, o regime de recursos das decisões das autoridades nacionais não tem em todos os Estados-Membros o carácter de recurso de plena jurisdição. Por conseguinte, conferir às decisões a força de presunção ilidível (sendo que no caso tal ilisão será, na generalidade dos casos, muito difícil) pode conflituar com o direito à proteção jurisdicional efetiva.

\section{(iv) Artigo 22." "Alterações à Lei de Organização do Sistema Judiciário"}

Todos os esforços e iniciativas dirigidos à obtenção de uma maior eficácia e celeridade na resolução dos processos judiciais são de louvar e apoiar. A maior eficácia e celeridade passa, em minha opinião, designadamente, pela especialização dos tribunais e pela homogeneidade na interpretação e aplicação das Leis, indispensável para a segurança jurídica. Mas, estas iniciativas, por implicarem sempre uma alteração mais ou menos profunda no sistema de justiça, têm de se traduzir em reformas viáveis e apoiadas por medidas concretas, eficazes e eficientes.

Antes de mais, importa chamar a atenção para uma aparente contradição entre o artigo $1 .^{\circ}$, n. ${ }^{\circ} 1$ deste projeto e a redação que o mesmo dá ao novo n. ${ }^{\circ} 4$ do artigo 112. ${ }^{\circ}$ da Lei de Organização do Sistema Judiciário (LOSJ). Trata-se de um anteprojeto de diploma de transposição de uma diretiva referente às ações de indemnização por infração às disposições do direito da concorrência. Tal é expressamente mencionado no que podemos chamar preâmbulo e reafirmado no artigo 1..$^{\circ}$ que, sob a epígrafe objeto e âmbito de aplicação, refere expressamente que "O presente diploma estabelece regras relativas a pedidos de indemnização por infração ao direito da concorrência...” 
Parecem não restar dúvidas de que o diploma versa exclusivamente sobre ações de indemnização, sendo deste modo que é conformado no artigo que versa sobre o seu objeto.

Sucede que para além de se propor aditar um n. 3 ao artigo $122 .^{\circ}$ da LOSJ, que versa sobre as ações de indemnização, propõe-se igualmente aditar um n. ${ }^{\circ} 4 \mathrm{em}$ que se atribui competência ao Tribunal da Regulação Concorrência e Supervisão (TRCS) refere a "todas as demais ações cíveis". Significa isto que o diploma vai mais além e tem um objeto mais vasto do que ele próprio define como sendo o seu objeto e que são as ações de indemnização por infração às normas da concorrência.

As razões que fundamentam a proposta de alteração da competência do TCRS são em teoria e em abstrato válidas:

1) especificidade das matérias de direito e economia da concorrência e na conveniência de que seja um tribunal especializado a lidar sempre com este tipo de matérias, para beneficio da qualidade das decisões judiciais e, em termos mais gerais, da boa administração da justiça e da melhoria da cultura jurídica de concorrência em Portugal.

2) ligação que, na maioria dos casos, haverá entre a ação de indemnização e o processo contraordenacional que investiga e sanciona a mesma infração ao direito da concorrência com vantagem em aproveitar o "know how" decorrente do julgamento no qual o tribunal escrutinou a decisão da $A d C$ que declarou a existência da infração que, depois, fundará o pedido de indemnização.

As vantagens da especialização são evidentes em qualquer jurisdição e, particularmente num direito com as especificidades do direito da concorrência. Permite um conhecimento mais profundo das matérias e contribui para a uniformidade da jurisprudência, garantindo a harmonia e coerência de todo o sistema jurídico.

Sucede que, analisando na prática o impacto desta nova competência, concluímos que esta argumentação é um pouco teórica.

O que propõe-se é atribuir ao TCRS competência para as:

"3 - Compete ao tribunal julgar ações de indemnização cujo pedido se fundamente exclusivamente em infrações ao direito da concorrência, ações destinadas ao exercício do direito de regresso entre coinfratores, bem como pedidos de acesso a meios de prova relativos a tais açoes, nos termos previstos no [DIPLOMA DE TRANSPOSIÇÃO].

4 -Compete ainda ao tribunal julgar todas as demais ações civis cujo pedido se fundamente exclusivamente em infrações ao direito da concorrência previstas nos artigos 9. ${ }^{\circ} 11 .^{\circ}$ e $12 .^{\circ}$ da Lei $n^{\circ}$ 19/2012, de 8 de maio, el ou nos artigos 101. ' e 102. 'do Tratado sobre o Funcionamento da União Europeia."

Há que chamar a atenção para o facto de não estar contemplada a atribuição de competência do TCRS para as medidas de preservação dos meios de prova que estão previstas no art. $17 .^{\circ}$ da proposta. Sabendo nós que a competência dos tribunais "especializados" é apenas e só a que constar da Lei, tendo competência residual as seções locais cíveis, convirá aditar esta competência no n. 3 para evitar potenciais conflitos de competência.

Entrando agora na análise das alterações propostas sobre a competência do TCRS importa considerar que, não obstante passar a haver um único tribunal competente para uma parte das ações e litígios relacionados com o direito da concorrência, continua a haver uma franja grande de processos, pode mesmo dizer-se a maior parte dos processos, que escapa a esta especialização.

Desde logo ficam excluídos por força da própria norma as ações em que a causa de pedir não resida unicamente numa infração ao direito da concorrência, bem como as ações em que o direito da concorrência é invocado em sede de defesa, ou seja, a 
maior parte das ações pendentes nos nossos tribunais.

Por outro lado, continua a haver uma franja considerável que permanece nos tribunais administrativos onde as ações de private enforcement têm vindo a aumentar.

De acordo com o estudo do CIDEEFF," o "histórico" das ações de private enforcement em Portugal são os seguintes:

"Nos últimos 5 anos completos (2011 a 2015), houve um total de 106 decisões judiciais de private enforcement da concorrência (excluindo Instituto da Vinha), numa média de 21,2 por ano. Em 2015 bouve 212\% mais decisões judiciais que em 2011. Mesmo admitindo um incremento da tendência de aumento do número de ações, para 250\% ao longo dos próximos 5 anos, chegaríamos a 2020 com um total de 265 decisoes judiciais nesse período de 5 anos, e uma média de 53 decisões por ano, em todas as instâncias e todos os tribunais do país. Estes números são, provavelmente, uma estimativa otimista.

$[\ldots]$

Assim, dos 88 casos de práticas restritivas analisados, só 7, no máximo, caberiam, possivelmente, no âmbito da competência do TCRS assim definida (menos de 8\%) Mas, num destes casos, os tribunais "corrigiram" o pedido da Autora para um pedido de direito civil. E em três outros é possivel que se tenham suscitado argumentos de direito regulatório el ou civil. Só 1 destes casos não é uma ação follow-on ou mista, e todas são ações recentes, podendo sugerir um processo evolutivo que leve no futuro a um maior número relativo de ações assim configuradas.

Significa isto que, numa previsão otimista (assente na manutenção do mesmo ritmo de prática decisória da $A d C$ ), a cláusula de centralização de casos no TCRS trará a este tribunal cerca de 3 casos por ano, em média, nos próximos anos, e a grande maioria dos casos em que se suscitam questões de private enforcement da concorrência continuarão a ser conhecidos por outros tribunais de $1^{a}$ instância."

Parece, pois, claro que não se vai operar uma verdadeira especialização no que concerne às ações de private enforcement.

De igual modo no que toca à especialização nos tribunais superiores a proposta apresenta algumas fragilidades.

Atualmente em $1^{\mathrm{a}}$ instância apenas existe especialização ao nível do public enforcement. As decisões da AdC são objeto de recurso para o TCRS e os recursos das decisões deste são interpostos para o Tribunal da Relação de Lisboa onde são distribuídos sempre à mesma secção criminal. Por sua vez, os recursos interpostos das decisões proferidas pelo Tribunal da Relação de Lisboa para o Supremo Tribunal de Justiça são sempre distribuídos à mesma secção criminal deste último - artigos $54 .^{\circ}$ e $74 .^{\circ}$ da LOSJ.

A proposta introduz alterações que me parecem incoerentes e que não contribuem para a especialização dos tribunais superiores.

- Proposta redação do artigo 54..$^{\circ}$ da LOSJ:

"As causas referidas no artigo 112." são sempre distribuidas à mesma secção criminal, com exceção das causas referidas nos n. 's 2 a 4 do artigo 112.", que são sempre distribuidas à mesma secção cível."

- Proposta de redação do artigo 67. ${ }^{\circ}$ da LOSJ:

"Até à instalação da seçãa de concorrência, regulação e supervisão, as causas referidas no artigo 112. "são sempre distribuidas à mesma seç̧ão".

Resulta da proposta, no que ao Supremo Tribunal de Justiça respeita, que se opta por uma especialização em dois planos distintos: private enforcement (cível) por um lado

\footnotetext{
${ }^{1}$ Disponível em: http://www.cideeff.pt/xms/files/Projeto_4_grupo_III/Jurisprudencia_de_Private_ Enforcement.pdf.
} 
e public enforcement (contra-ordenação), por outro. Isto resulta da proposta de alteração do artigo $54 .^{\circ}$ que expressamente atribui a competência separadamente para as causas previstas no n. ${ }^{\circ} 1$ (public enforcement) do artigo 112. ${ }^{\circ}$ da LOSJ, das previstas nos n. ${ }^{\circ \mathrm{s}} 2^{\circ}$ a 4. ${ }^{\circ}$ (administrativo e private enforcement) do mesmo artigo, respetivamente a uma secção criminal e a uma secção cível.

Já ao nível do Tribunal da Relação parece que o objetivo, até ser criada uma secção de concorrência, regulação e supervisão, que muito dificilmente vai algum dia existir por o número de processos não o justificar, é de atribuir a competência a uma única secção. A questão que se coloca é saber qual a secção a que se vai atribuir a competência. Será uma secção cível ou uma secção criminal? E quem determina qual a secção competente? O presidente da Relação de Lisboa decidir?

A diferente redação deste artigo no confronto com a proposta para o art. 54. ${ }^{\circ}$ não permite outra interpretação, designadamente não permite entender que se pretende dividir a matéria contra-ordenacional da matéria cível e atribuir a competência para a primeira a uma secção criminal e para a segunda a uma secção cível.

Em suma, passamos a ter um único tribunal de primeira instância competente para conhecer todas as causas previstas no art. 112..$^{\circ}$ uma única secção do Tribunal da Relação de Lisboa competente para conhecer essas mesmas causas, mas depois, ao nível do Supremo Tribunal de Justiça, essa competência encontra-se repartida por uma secção criminal e outra cível.

Parece estar posta em causa não só a coerência do sistema como também a verdadeira especialização dos tribunais superiores. 